\title{
Knowledge Management through Technology: Exploring Extant Research Using nVivo
}

\author{
Vinay Kumar Sharma, Madhurima Deb \\ Indian Institute of Management, Kashipur, India \\ Email: vinay.sist@yahoo.com, madhurima.deb@iimkashipur.ac.in
}

How to cite this paper: Sharma, V.K. and Deb, M. (2019) Knowledge Management through Technology: Exploring Extant Research Using nVivo. Theoretical Economics Letters, 9, 761-770. https://doi.org/10.4236/tel.2019.94050

Received: January 12, 2019

Accepted: April 5, 2019

Published: April 8, 2019

Copyright ( 2019 by author(s) and Scientific Research Publishing Inc. This work is licensed under the Creative Commons Attribution International License (CC BY 4.0).

http://creativecommons.org/licenses/by/4.0/

\section{cc) (i) Open Access}

\begin{abstract}
This research paper aims to systematically explore the knowledge management and knowledge management system through technology by performing a rigorous and computer assisted review. The research attempts to further the understanding of issued and innovations related to knowledge management in organizations and helps us see the future avenues in this field. The key contribution of this research is its computer based qualitative content analysis across genres to attain the above objectives. The finding of the study suggests that Knowledge Management is spread across three factors namely, 1) Knowledge acquisition, 2) Knowledge application, and 3) Knowledge storage. These three factors are linked to IT platform or technology then it leads to dissemination, awareness, accessibility etc of the Knowledge.
\end{abstract}

\section{Keywords}

Knowledge, Knowledge Management, Technology, Literature Review, nVivo

\section{Introduction}

In this competitive global era, innovation is an area of the utmost importance for nations, organizations and individuals. Everyone in today's world is working to trace effective ways to foster innovations for business success, sustainable development and competitive advantage. The concept of Knowledge Management (KM) has been acknowledged by academicians and industry practitioners as an important element of the innovation process. The concept of KM came into existence during the 90's and had attracted the interest of both the practioners and the researchers. It had been found that sometimes organizations face disappointing results and dissatisfaction due to the poor and immature implementation of KM [1]. 
Today's Competitive organizations are looking for Technology led Knowledge Management to augment their business process with dynamic innovative practices. It had been found that gaps exist between Knowledge Management and Technology adaptation. In Knowledge Management process technology works as an instrument that complements creativity, leading to the dissemination and utilisation of knowledge to achieve organization specific objectives. Technology is a medium for transfer of knowledge which allows for the incorporation, sharing and understanding of new content. Technological tools nowadays work as facilitators and practical instrument for knowledge integration.

Knowledge Management through implementation of technology is inevitable. Prior research shows a worldwide usage of technology for KM in all sectors. The advent of information technology brought greater speed, agility, sharing, collaboration and efficiency in Knowledge Management. According to researchers, implementation of technology is strategically essential for a global presence when organizations are operating in many geographically distant locations and technology becomes process oriented from supporting a functional system [2]. Without the practical inclusion of technology a KM system cannot operate effectively and practitioners will have difficulty to manage their intellectual capital [3]. The present work attempts to look into the existing literature on KM to explore studies done on KM. What are the consequences of integrating KM system using technology?

Knowledge Management-extant research

We live in $21^{\text {st }}$ century society where knowledge is the source of the highest reflective and quality power [4]. This "knowledge-based society" is defined by the knowledge economy, where success depends on the quality of knowledge which organizations apply to their major business processes [5]. Knowledge is a reflective instrument that effectively increases an organization's capacity to implement the right and intensive action [6]. Knowledge can be characterized into two forms, which are tacit and explicit knowledge [7]. Tacit knowledge can be attained through imitation and practice and it is embedded inside a person [8]. Explicit knowledge is described as information written in a formal language and further expressed in the form of rules, principles and guidelines [9]. Tacit knowledge rests with the employee and explicit knowledge is espoused knowledge. Conversion of knowledge from one form to another occurs frequently and often leads to the creation of new knowledge [10]. Knowledge management becomes the need of organizations which automatically comes from the consequence of the link between competitive advantage and knowledge. Two different segments exist in the Knowledge Management system. In one segment practioner's maintain that organizational behavior and individual socialization that determine how much knowledge passes between individuals. They generally believe that technology is not the answer, but rather a distraction from issues such as change management, culture and leadership. In other segment of the spectrum, are information technology evangelists, who focus on technology as the solution to the Knowledge Management [11]. 
Most research to date has shown that a successful Knowledge Management programme requires a change in organizational behavior and in technology infrastructure [12]. Technology is not the solution to an organization's Knowledge Management needs, but it is clearly required to enable the organization's Knowledge Management processes [13].

An organization's Knowledge Management system is the collection of allied technologies and information technologies used to collect, organize, transfer and distribute knowledge among employees [14]. A Knowledge Management System works between Individuals, from Individuals to explicit sources, from Individuals to groups, between groups, across groups and from the group to the organization [15]. A reliable and effective Knowledge Management System can reduce management errors and improve services and efficiency, improve decision making, create less work and reduce redundant work and increase organizational knowledge (Rockart et al., 1996).

\section{Research Design}

\section{1) Research methodology and paradigm}

Researcher decided to investigate the knowledge management through technology in the organizations systematically from an interpretive/constructivist paradigm since the extant work in this area is limited and dispersed. Since one of the objectives of this research was to coherently organize the past research to discover future possibilities, qualitative literature analysis seemed to be the most appropriate approach. Qualitative research bestows on a researcher the necessary contextual tools and inductive logic that can help in the exploration of complex phenomenon.

\section{2) Data collection process}

The "selection process", i.e. how the research papers were chosen, itself involved two sub-phases viz. journal selection and paper selection. Literature review began with a keyword search from several literature databases, giving access to a broad spectrum of international and peer reviewed Knowledge management journals. Researcher searched EBSCO/Business Source Complete, Proquest/ABI Inform and Science Direct to start with. Our searches identified 698 citations. We screened 123 full-text articles for eligibility (excluding editorials, articles without abstract, proceedings etc) out of 123 only 16 were included in the study that had used the construct of technology to explain the consequences of KM system build in the organization. (The 16 that were included in the study are; Maria Martensson, 2000; Carlo Rizzi et al., 2009; Sandra et al., 2003; Peter Massingham, 2014; Michael Heffner \& Nawaz Sharif, 2008; Voon-Hsien et al., 2013; Mirghani Mohamed et al., 2006; Jing Tian et al., 2006; Steve Offsey, 1997; John S et al., 2006; Sohel Ahmad Roger \& G. Schroeder, 2011; Elayne Coakes et al., 2010; Josephine Chinying Lang, 2001; Fei Gao Meng Li \& Yoshiteru Nakamori, 2002; Renee M. Wachter, 1999; Mats Edenius Janet Borgerson, 2003).

Researcher then reviewed the abstracts of all articles of our literature base to 
check for relevance to our research study. Of these, four studies were assessed as high quality, ten were rated moderate quality and two studies were of poor quality (methodological and/or reporting quality). This was the first phase of our literature review. Now to look at coherence and gaps in this literature, we needed to categorize these articles into broad themes (Sarkar and Cavusgil, 1996). For this we relied on Qualitative Data Analysis using the widely used software called nVivo.

\section{Data Analysis}

Qualitative analysis of the archival data involved the following steps:

1) Content Analysis-Content analysis is a research method for making replicable and valid inferences from data to their context, with the purpose of providing knowledge, new insights, a representation of facts and a practical guide to action [16]. The aim during the course of this research was to attain a condensed and broad description of "knowledge management through technology". The analysis would help us delve into the concepts (and categories) describing this phenomenon [17].

2) The qualitative analysis and literature review-The qualitative analysis and literature review was done with the help of Qualitative Data Analysis (QDA) software called nVivo [18]. Qualitative data analysis software is often thought to be based on grounded theory approaches to data analysis in that theory will emerge from the data and the software often has "memoing" tools which facilitate theory building from the data. Taking a grounded theory approach to data analysis means allowing the data to "speak for themselves" rather than approaching the data within, for example, existing theoretical frameworks [19]. This analysis helped us in viewing the past literature from a bird's eye. Themes and concepts in the form of networks started to emerge. The thematic network shown in Figure 1 better envisages this fact. Section 5, further throws light on

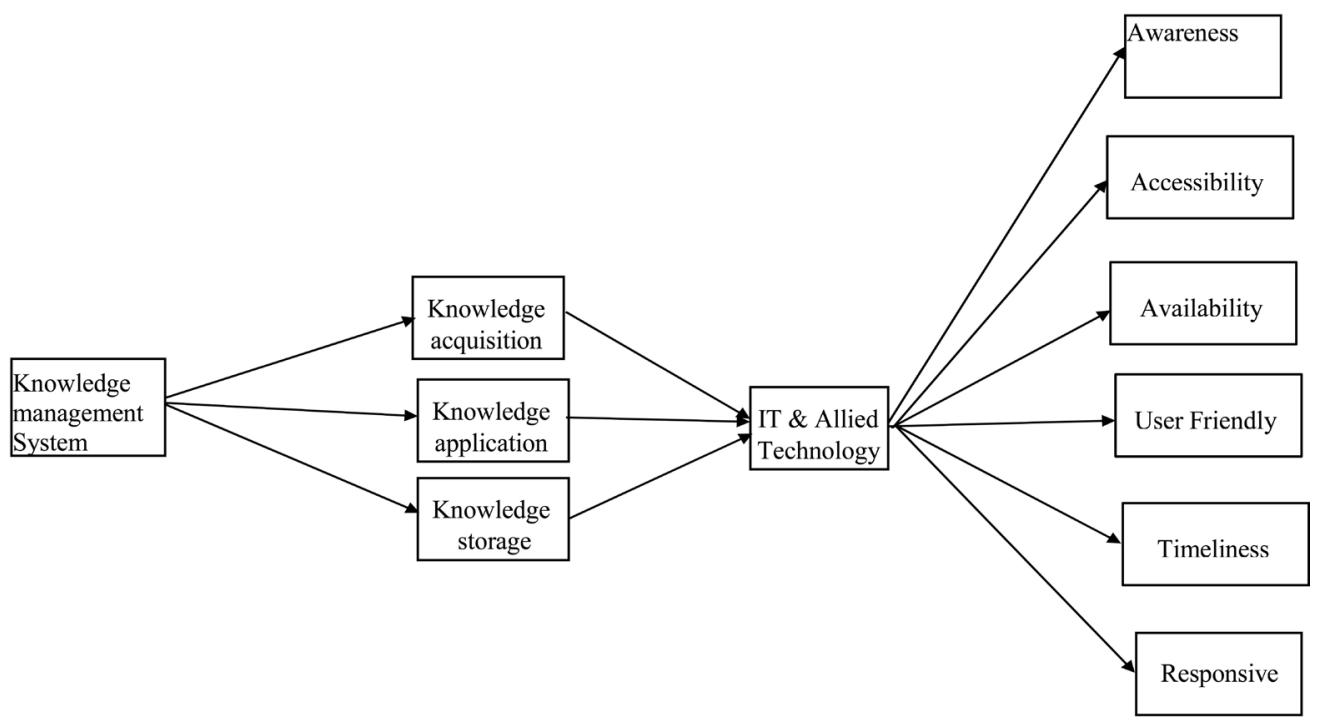

Figure 1. Thematic network model of the emergent themes. 
each of these themes-individually and collectively.

\section{Results}

Knowledge management system is the collection of allied technologies and information technologies actively involved to collect, organize and distribute desired and intensive knowledge among employee and participative components. There are some specific technologies available now days for constructing a knowledge management system. Organizations have created desired knowledge management system to achieve desired goal. A well designed knowledge management system can convert from learning organization to effective and efficient organization. Creating an effective knowledge management system is not a simple task; it takes a lot of efforts and technology support.

It had been found that technology led knowledge management system have many benefits [15];

- Awareness-Technology led management system enable to people where to go to find the organization's knowledge, saving people time and effort.

- Accessibility-Technology used in knowledge management system is pervasive in organization after the introduction of intranet, internet and some specific software. All concerns can use the organization's combined knowledge and experience in their professional roles.

- Availability-After the introduction of movable ICT Knowledge is usable wherever it is needed. This increases prompt responsiveness to intended persons/authorities.

- Timeliness-After inception of allied and information technology intended Knowledge is available whenever it is required, eliminating time-wasting distribution of information.

- User-friendly-Simplified nature of technology enable users to gain knowledge. A good knowledge management system contains easy handling IT tools and help options for users.

- Responsiveness-A technology led management system provide prompt and responsive platform to users and intended persons.

Knowledge management system should be customizable, measurable and secure. Knowledge management should contain customize supply user interface templates so user can easily customize them by using familiar IT tools [20]. System should allow integration of existing and new application. Measurement create right balance between organizational change and technological change. Knowledge management system should provide tools that allow users to measure a clear blue print, trace output bottlenecks and especially use the desired data to improve the exchange process of knowledge [21]. Recent knowledge management system focus on pervasive access this does not means that system do not have security. Modern knowledge management system provide repositories and preserve security.

Past researches advocate that the knowledge management system contains 
three major components knowledge acquisition, knowledge application and knowledge storage. Knowledge acquisition focusing on locating, crating and discovering new information [22]. Knowledge can be acquired from different sources and can be used as a tool to solve the issues facing company. Knowledge can be gathered from various sources who is part of the knowledge environment. Knowledge application or knowledge responsiveness, simply means a firm responding to the different types of information it has access to [23]. Through the inception of effective knowledge application, the organisations are able to enhance their productivity. Knowledge storage is considered one of the most essential elements in the KM process as it helps in the prevention of losing important information. Knowledge storage is referred to as a process of structuring and storing of knowledge. It formalizes knowledge and provides the possibility of utilizing it in future. Knowledge storage is similar to organisational memory, in which it enables an individual to store, integrate, and reuse the information again in future [24].

Allied technologies and Information technologies have imparted aspects of knowledge management from long age. Reality is that, in the world there is no single technology available to fill all aspects required for knowledge management system because knowledge management system is not only technology driven system [25]. Knowledge management system is a multi-disciplinary field required attention of technology, behavioural aspects, communication and analysis. Desired output can achieve to incorporate the role specific technologies in the system [26].

Intranet become famous across organizations because it provide ideal environment for information sharing but it is limited to small and medium sized organizations [27]. In large organizations it does not work effectively and was found low responsive. Practioners believe that all the organization's knowledge should be transferred to the intranet [28]. Intranet requires the technology infrastructure and web server for a content repository. Now a days websites are used for managing content but intranet site is essential to provide intended information and knowledge to the right person [29].

Document management system is used as repositories for organizations documents and provides the explicit knowledge access [30]. We can create and process complex documents with the help of DMS. It had been found that users resist using well-structured document management system and avoid creating and processing complex documents. Past researches advocate that document management system must be a part of infrastructure but rarely used by organizations [31]. Information retrieval technology exists in knowledge management system in the form of text repositories or intranet and concern with information seekers. Text repositories can be better integrated when organization's knowledge management system is ready to open standards [32].

After the introduction of Internet, intranets, extranets, CD-ROM/DVDROM and other new delivery systems, the management system of organization knowledge has become critical at some extent. Organizations are introducing 
and integrating enterprise-level electronic publishing systems. Integrating publishing capabilities with a Knowledge Management system allows users to present information in a consistent format regardless of its source, author or location [33].

Organizations use groupware systems within workgroups or departments to communicate and collaborate with each other [34]. Groupware provide platform for formal and ad hoc conversations when the users cannot communicate in real time. Push Technologies automate the exchange of information to end-users [35]. Although e-mail served this purpose for over a decade, new web-based technologies have added better presentation, real-time updates, and the ability to push applications as well as content. Content push is a dynamic form of electronic publishing and is therefore an important feature of a Knowledge Management system [36]. Agents are a specialized component of push technology. Agents are controlled by end-users who can specify the type of knowledge they want to receive [37]. A Knowledge warehouse provides an effective and efficient environment to the knowledge management system. Knowledge warehouse allows users to submit valuable knowledge even when they are not frequent contributors [38]. This eliminates the need for all end-users in the organization to install and maintain complex client software.

\section{Implications}

\subsection{Theoretical Implication}

The results presented in this research paper have great significance to the practitioners and researchers in the field of Knowledge management. Organizations can enjoy sustainable success through proper implementation of technology led knowledge management system. From the theoretical perspective, this study provided a detailed description between knowledge management system and technology. The literature review indeed offers a systematic framework to improve knowledge management through the integration of allied and Information technology. In general, the technology led knowledge management system has been proven effective records to achieve organization's objectives.

\subsection{Managerial Implication}

The results obtained from the literature review serves as pathway to practitioners for better application of knowledge management technology. Organizations need to identify the opportunities for better application of technology and devote more attention to apply innovative technologies to deemed fit for changing working pattern. Knowledge management environment contains knowledge management elements which is most important to ensure success of the KM system. Continuous monitoring of knowledge management system is required so that changes can be made as per the demand of intended individual and demanding competitive business environment. Balance should be established between business environment change and organizational change. 


\section{Conflicts of Interest}

The authors declare no conflicts of interest regarding the publication of this paper.

\section{References}

[1] Poppo, L. and Lacity, M.C. (2006) The Normative Value of Transaction Cost Economics: What Managers Have Learned about TCE Principles in the IT Context. In: Hirschheim, R., Heinzl, A. and Dibbern, J., Eds., Information Systems Outsourcing, Springer, Berlin, 259-282. https://doi.org/10.1007/978-3-540-34877-1_10

[2] Von Zedtwitz, M. and Gassmann, O. (2002) Market versus Technology Drive in R\&D Internationalization: Four Different Patterns of Managing Research and Development. Research Policy, 31, 569-588. https://doi.org/10.1016/S0048-7333(01)00125-1

[3] Bollinger, A.S. and Smith, R.D. (2001) Managing Organizational Knowledge as a Strategic Asset. Journal of Knowledge Management, 5, 8-18. https://doi.org/10.1108/13673270110384365

[4] Nonaka, I., Toyama, R. and Konno, N. (2005) SECI, Ba and Leadership: A Unified Model of Dynamic Knowledge Creation. Long Range Planning, 33, 5-34. https://doi.org/10.1016/S0024-6301(99)00115-6

[5] Cruz Galve, M. (2009) A Systematic Framework to Improve Knowledge Management through Information Technology. Doctoral Dissertation, University of Missouri, Columbia.

[6] Bierly, P.E., Kessler, E.H. and Christensen, E.W. (2000) Organizational Learning, Knowledge and Wisdom. Journal of Organizational Change Management, 13, 595 618. https://doi.org/10.1108/09534810010378605

[7] Grant, R.M. (1996) Toward a Knowledge-Based Theory of the Firm. Strategic Management Journal, 17, 109-122. https://doi.org/10.1002/smj.4250171110

[8] Nonaka, I. (1994) A Dynamic Theory of Organizational Knowledge Creation. Organization Science, 5, 14-37. https://doi.org/10.1287/orsc.5.1.14

[9] Cowan, R., David, P.A. and Foray, D. (2000) The Explicit Economics of Knowledge Codification and Tacitness. Industrial and Corporate Change, 9, 211-253. https://doi.org/10.1093/icc/9.2.211

[10] Lindvall, M., Rus, I. and Sinha, S.S. (2003) Technology Support for Knowledge Management. In: Althoff, K.-D., Feldmann, R.L. and Müller, W., Eds., Advances in Learning Software Organizations, Springer Berlin, 94-103. https://doi.org/10.1007/978-3-540-40052-3_9

[11] Malhotra, Y. (2005) Integrating Knowledge Management Technologies in Organizational Business Processes: Getting Real Time Enterprises to Deliver Real Business Performance. Journal of Knowledge Management, 9, 7-28. https://doi.org/10.1108/13673270510582938

[12] Bontis, N. (1999) Managing Organisational Knowledge by Diagnosing Intellectual Capital: Framing and Advancing the State of the Field. International Journal of Technology Management, 18, 433-462. https://doi.org/10.1504/IJTM.1999.002780

[13] Bhatt, G.D. (2001) Knowledge Management in Organizations: Examining the Interaction between Technologies, Techniques, and People. Journal of Knowledge Management, 5, 68-75. https://doi.org/10.1108/13673270110384419 
[14] McDermott, R. (2000) Why Information Technology Inspired but Cannot Deliver Knowledge Management. Knowledge and Communities, 41, 21-35. https://doi.org/10.1016/B978-0-7506-7293-1.50005-6

[15] Alavi, M. and Leidner, D.E. (2001) Review: Knowledge Management and Knowledge Management Systems: Conceptual Foundations and Research Issues. MIS Quarterly, 25, 107-136. https://doi.org/10.2307/3250961

[16] Elo, S. and Kyngäs, H. (2008) The Qualitative Content Analysis Process. Journal of Advanced Nursing, 62, 107-115. https://doi.org/10.1111/j.1365-2648.2007.04569.x

[17] Starks, H. and Trinidad, S.B. (2007) Choose Your Method: A Comparison of Phenomenology, Discourse Analysis, and Grounded Theory. Qualitative health research, 17, 1372-1380. https://doi.org/10.1177/1049732307307031

[18] Bringer, J.D., Johnston, L.H. and Brackenridge, C.H. (2006) Using Computer-Assisted Qualitative Data Analysis Software to Develop a Grounded Theory Project. Field Methods, 18, 245-266. https://doi.org/10.1177/1525822X06287602

[19] Welsh, E. (2002) Dealing with Data: Using NVivo in the Qualitative Data Analysis Process. Forum Qualitative Sozialforschung, 3, Article No. 26.

[20] Offsey, S. (1997) Knowledge Management: Linking People to Knowledge for Bottom Line Results. Journal of Knowledge Management, 1, 113-122. https://doi.org/10.1108/EUM0000000004586

[21] Klusch, M. (2001) Information Agent Technology for the Internet: A Survey. Data \& Knowledge Engineering, 36, 337-372. https://doi.org/10.1016/S0169-023X(00)00049-5

[22] Benbya, H., Passiante, G. and Belbaly, N.A. (2004) Corporate Portal: A Tool for Knowledge Management Synchronization. International Journal of Information Management, 24, 201-220. https://doi.org/10.1016/j.ijinfomgt.2003.12.012

[23] Darroch, J. and McNaughton, R. (2002) Examining the Link between Knowledge Management Practices and Types of Innovation. Journal of Intellectual Capital, 3, 210-222. https://doi.org/10.1108/14691930210435570

[24] Vander Spek, R. and Spijkervet, A. (1997) Knowledge Management: Dealing Intelligently with Knowledge. In: Liebowitz, J. and Wilcox, Lyle C., Eds., Knowledge Management and Its Integrative Elements, CRC Press, Boca Raton, 31-59.

[25] Marwick, A.D. (2001) Knowledge Management Technology. IBM Systems Journal, 40, 814-830. https://doi.org/10.1147/sj.404.0814

[26] Sasson, J.R. and Douglas, I. (2006) A Conceptual Integration of Performance Analysis, Knowledge Management, and Technology: From Concept to Prototype. Journal of Knowledge Management, 10, 81-99. https://doi.org/10.1108/13673270610709233

[27] Riege, A. (2005) Three-Dozen Knowledge-Sharing Barriers Managers Must Consider. Journal of Knowledge Management, 9, 18-35. https://doi.org/10.1108/13673270510602746

[28] Holsapple, C.W. and Singh, M. (2001) The Knowledge Chain Model: Activities for Competitiveness. Expert Systems with Applications, 20, 77-98. https://doi.org/10.1016/S0957-4174(00)00050-6

[29] Stoddart, L. (2001) Managing Intranets to Encourage Knowledge Sharing: Opportunities and Constraints. Online Information Review, 25, 19-29. https://doi.org/10.1108/14684520110366661

[30] Staab, S., Studer, R., Schnurr, H.P. and Sure, Y. (2001) Knowledge Processes and Ontologies. IEEE Intelligent Systems, 16, 26-34. 
https://doi.org/10.1109/5254.912382

[31] Mendonça, D. (2007) Decision Support for Improvisation in Response to Extreme Events: Learning from the Response to the 2001 World Trade Center Attack. Decision Support Systems, 43, 952-967. https://doi.org/10.1016/j.dss.2005.05.025

[32] Liebowitz, J. (2001) Knowledge Management and Its Link to Artificial Intelligence. Expert Systems with Applications, 20, 1-6. https://doi.org/10.1016/S0957-4174(00)00044-0

[33] Allen, D. (2012) Enterprise Content Management Best Practices: ECM Strategy 100 Most Asked Questions-Solve Your Information Management Challenges on Email Management, Search, Records Management, Compliance, and More. Emereo Publishing, Brisbane.

[34] Grudin, J. (1994) Computer-Supported Cooperative Work: History and Focus. Computer, 27, 19-26. https://doi.org/10.1109/2.291294

[35] Bullen, C.V. and Bennett, J.L. (1990) Learning from User Experience with Groupware. 1990 ACM Conference on Computer-Supported Cooperative Work, Los Angeles, 7-10 October 1990, 291-302. https://doi.org/10.1145/99332.99362

[36] Zack, M.H. (1999) Managing Codified Knowledge. Sloan Management Review, 40, 45-58.

[37] Jennings, N.R. (2001) An Agent-Based Approach for Building Complex Software Systems. Communications of the ACM, 44, 35-41.

https://doi.org/10.1145/367211.367250

[38] Davenport, T.H. and Prusak, L. (1998) Working Knowledge: How Organizations Manage What They Know. Harvard Business Press, Cambridge. 